\title{
Integrating Temperature with Odor Processing in the Olfactory Bulb
}

\author{
Eugen Kludt, ${ }^{1,4}$ Camille Okom, ${ }^{1,2 \star}$ Alexander Brinkmann, ${ }^{1,2 \star}$ and Detlev Schild ${ }^{1,2,3,4}$ \\ ${ }^{1}$ Institute of Neurophysiology and Cellular Biophysics, University of Göttingen, 37073 Göttingen, Germany, ${ }^{2}$ Center for Nanoscale Microscopy and \\ Molecular Physiology of the Brain, Georg-August-Universität Göttingen, 37073 Göttingen, Germany, ${ }^{3}$ DFG Excellence Cluster 171, University of Göttingen, \\ 37073 Göttingen, Germany, and ${ }^{4}$ Bernstein Center for Computational Neuroscience, 37073 Göttingen, Germany
}

Temperature perception has long been classified as a somesthetic function solely. However, in recent years several studies brought evidence that temperature perception also takes place in the olfactory system of rodents. Temperature has been described as an effective stimulus for sensory neurons of the Grueneberg ganglion located at the entrance of the nose. Here, we investigate whether a neuronal trace of temperature stimulation can be observed in the glomeruli and mitral cells of the olfactory bulb, using calcium imaging and fast line-scanning microscopy. We show in the Xenopus tadpole system that the $\gamma$-glomerulus, which receives input from olfactory neurons, is highly sensitive to temperature drops at the olfactory epithelium. We observed that thermo-induced activity in the $\gamma$-glomerulus is conveyed to the mitral cells innervating this specific neuropil. Surprisingly, a substantial number of thermosensitive mitral cells were also chemosensitive. Moreover, we report another unique feature of the $\gamma$-glomerulus: it receives ipsilateral and contralateral afferents. The latter fibers pass through the contralateral bulb, cross the anterior commissure, and then run to the ipsilateral olfactory bulb, where they target the $\gamma$-glomerulus. Temperature drops at the contralateral olfactory epithelium also induced responses in the $\gamma$-glomerulus and in mitral cells. Temperature thus appears to be a relevant physiological input to the Xenopus olfactory system. Each olfactory bulb integrates and codes temperature signals originating from receptor neurons of the ipsilateral and contralateral nasal cavities. Finally, temperature and chemical information is processed in shared cellular networks.

Key words: activity correlation imaging; chemosensitivity; integration; mitral cells; olfactory bulb; thermosensitivity

\section{Introduction}

Several studies on olfaction have brought new facets to our understanding of temperature coding in the nose. Neurons of the Grueneberg ganglion (GG) of the mouse were shown to respond to chemosensory cues, including alarm pheromones as well as cool ambient temperatures (Brechbühl et al., 2008, 2013; Mamasuew et al., 2008, 2011; Hanke et al., 2013). These cells show a graded and temperature-dependent $\mathrm{Ca}^{2+}$ influx at their somata (Schmid et al., 2010), and their axons project to the so-called necklace glomeruli in the olfactory bulb (Fuss et al., 2005; Koos and Fraser, 2005; Fleischer et al., 2006; Roppolo et al., 2006; Storan and Key, 2006). The temperature-sensing transduction mechanisms in these neurons via a cGMP-mediated cascade have

\footnotetext{
Received Feb. 9, 2015; revised March 30, 2015; accepted April 13, 2015

Author contributions: E.K., C.O., A.B., and D.S. designed research; E.K., C.O., and A.B. performed research; E.K., C.O., A.B., and D.S. analyzed data; E.K., C.O., A.B., and D.S. wrote the paper.

This project was funded by the Deutsche Forschungsgemeinschaft Excellence Cluster 171; the Center for Nanoscale Microscopy and Molecular Physiology of the Brain; and the Bernstein Center for Computational Neuroscience (FKZ01GQ1005A) and the European Neuroscience Campus Network, an Erasmus Mundus Joint Doctoral Program. We thank Stephan Junek and Mihai Alevra for providing MATLAB codes for image evaluation, especially MatVis.

${ }^{*}$ C.O. and A.B. contributed equally to this study.

The authors declare no competing financial interests.

Correspondence should be addressed to Detlev Schild, Institute of Neurophysiology and Cellular Biophysics,

University of Göttingen, Humboldtallee 23, 37073 Göttingen, Germany. E-mail: dschild@gwdg.de.

E. Kludt's present address: German Hearing Center Hannover, 30625 Hannover, Germany.

DOI:10.1523/JNEUROSCI.0571-15.2015

Copyright $\odot 2015$ the authors $\quad 0270-6474 / 15 / 357892-11 \$ 15.00 / 0$
}

been characterized lately in mice and in other rodents (Mamasuew et al., 2010; Brechbühl et al., 2014; Chao et al., 2015). Thermosensitivity thus appears not to be restricted to the Grueneberg system of the mouse. These findings open up a number of intriguing questions about how chemosensory signal processing might be affected or modulated by temperature. Can the parallel processing of odors and temperature also be found in the olfactory system of other vertebrates? Is the thermosensitivity at the periphery of the system reflected in the activity of the olfactory bulb? If so, is the effect confined to the presynaptic glomerular compartments, or are cool stimuli conveyed transglomerularly to mitral cells and higher brain centers? Here we approach the latter questions; that is, how and where temperature information is processed at the level of the olfactory bulb in premetamorphic Xenopus laevis, a lower vertebrate.

In these animals, the olfactory bulb spans four main layers along the rostrocaudal axis: the nerve layer with its sorting zone; the glomerular layer; the mitral cell layer; and the granule cell layer. The glomerular layer is often considered the first relay station of olfactory processing. It is a dense meshwork of fibers of receptor neurons, mitral cells, and periglomerular cells. Presynaptic axon terminals of receptor neurons and postsynaptic dendritic branches of mitral cells intermingle and form glomeruli, skein-like neuropil structures that are rich in synapses. The glomerular layer of the ventral olfactory bulb can be subdivided into clusters of glomeruli (Gaudin and Gascuel, 2005; Manzini et al., 
2007b). Along the mediolateral axis, one can distinguish medial, small, intermediate, and lateral clusters. Each of them comprises $\sim 100,70,175$, and 5 glomeruli, respectively (Manzini et al., $2007 b$ ). Odor representation in the olfactory bulb is chemotopic. Glomeruli belonging to the lateral cluster are amino acid sensitive, whereas glomeruli lying within the medial cluster generally respond to the application of alcohols, among others (Gliem et al., 2013). Insofar, the cues activating the glomeruli of the small and intermediate clusters have remained elusive.

Our analysis led us to the identification of a glomerulus in the small cluster that solely specialized in the detection of cool temperatures. We demonstrate that some cells in the main olfactory epithelium of $X$. laevis are thermosensitive and that temperature information is further processed by olfactory bulb neurons. Specifically, we observed that a number of mitral cells sensitive to amino acids, which are known odorants in this species, also responded to temperature. Moreover, the ratio of chemosensitivity to thermosensitivity varied between different mitral cells. Furthermore, we describe an entirely novel innervation pattern in which the $\gamma$-glomerulus receives primary afferents from the contralateral olfactory epithelium via the anterior commissure, thus providing olfactory information originating from both nasal cavities to the same glomerulus.

\section{Materials and Methods}

Animals. The experiments were performed on male and female X. laevis tadpoles (stages 47-54; Nieuwkoop and Faber, 1994) according to guidelines approved by the Göttingen University Committee of Ethics in Animal Experimentation.

Solutions. The standard Ringer's solution contained the following (in mM): $98 \mathrm{NaCl}, 2 \mathrm{KCl}, 1 \mathrm{CaCl}_{2}, 2 \mathrm{MgCl}_{2}, 5$ glucose, $5 \mathrm{Na}$-pyruvate, and 10 HEPES. It was adjusted to $\mathrm{pH} 7.8$ and $230 \mathrm{mOsmol} / \mathrm{L}$. For testing possible $\mathrm{pH}$ effects upon the $\gamma$-glomerulus, the $\mathrm{pH}$ of the standard Ringer's solution was adjusted to 8.3 or 7.3. For stimulus application, odorants were diluted in Ringer's solution and stored for up to $5 \mathrm{~d}$ at $4^{\circ} \mathrm{C}$. The following odorant mixtures were used: (1) amino acids: L-alanine, L-arginine, L-asparagine, L-aspartate, L-cysteine, L-glutamate, L-glutamine, L-glycine, L-histidine (His), L-isoleucine, L-leucine, L-lysine, L-methionine, L-phenylalanine, L-proline, L-serine, L-threonine, L-tryptophan, and L-valine (200 $\mu \mathrm{M}$ each); (2) amines: 2-phenylethylamine, tyramine, butylamine, cyclohexylamine, hexylamine, 3-methylbutylamine, $\mathrm{N}, \mathrm{N}$ dimethylethylamine, 2-methylbutylamine, 1-formylpiperidine, 2-methylpiperidine, $N$-ethylcyclohexylamine, 1-ethylpiperidine, and piperidine (200 $\mu \mathrm{m}$ each); (3) alcohols (after work by Altner, 1962): $\beta$-ionone, citral, $\beta$-phenylethyl alcohol, and $\gamma$-phenylpropyl alcohol (200 $\mu \mathrm{M}$ each); (4) bile acids (Sigma-Aldrich): taurocholic acid $(200 \mu \mathrm{M})$, and traces of glycocholic, deoxycholic, and other bile acids; (5) nucleotides: adenosine, AMP, ADP, ATP, uridine, uridine-5' -triphosphate, cytidine-5' -triphosphate, and GTP (100 $\mu \mathrm{m}$ each); and (6) pyrazines: pyrazine, 2-methylpyrazine, lutidine, 2,3-dimethylpyrazine, and 2,5-dimethylpyrazine (100 $\mu \mathrm{M}$ each).

Forskolin $(50 \mu \mathrm{M}), 1$-methyl-3-isobutylxanthine (IBMX; $50 \mu \mathrm{M}$ ), and 8-bromoguanosine (8Br)-cGMP (1 mM), activators of the adenylyl and guanylyl cyclases, were used to mimic chemical stimulation in olfactory sensory neurons (OSNs) using the cAMP or cGMP transduction pathways (Manzini and Schild, 2003). If not stated otherwise, chemicals were purchased from Sigma-Aldrich or Merck.

Electroporation. The electroporation of X. laevis olfactory epithelium was performed as previously described (Junek et al., 2010). Briefly, the tadpoles were anesthetized with $0.02 \%$ MS-222 (w/v) for at least $1 \mathrm{~min}$. The anesthetized animals were transferred onto a silicone cushion within a Petri dish, and the water in the nasal cavities was removed by softly soaking it up with a piece of tissue paper. Small crystals of $10 \mathrm{kDa}$ dextran-conjugated dye (Alexa Fluor 488, Alexa Fluor 568, Alexa Fluor 647, and Fluo-4; Invitrogen) were placed into the nasal cavity. These crystals dissolved within $1 \mathrm{~min}$. Two platinum electrodes were then in- serted into the nasal cavities without damaging the tissue. Twelve $30 \mathrm{~V}$ square pulses of $20 \mathrm{~ms}$ duration were applied at $1 \mathrm{~Hz}$ with alternating polarity. The animals were then put back into an aquarium. They were kept at a low-light regime and under otherwise normal conditions for 1-7 $\mathrm{d}$ before the experiments. The anterograde axonal transport of 10 $\mathrm{kDa}$ dextran to the axon terminals in the olfactory bulb required $\sim 1 \mathrm{~d}$.

Whole-mount tissue preparation and bolus loading. X. laevis tadpoles were anesthetized in a mixture of water and ice, and decapitated. A rectangular block containing the forebrain and the nose was cut out leaving the olfactory bulbs, the olfactory nerves, and the olfactory epithelia intact. The connective tissue ventral to the telencephalon was cut away to expose the olfactory bulb. The resulting explant preparation was placed into Ringer's solution. Bulk staining of the olfactory bulb was achieved by pressure injection of Fluo-4 acetoxymethyl (AM), as previously described (Junek et al., 2010). Briefly, a patch pipette (resistance, 5-8 M $\Omega$; tip diameter, $1-2 \mu \mathrm{m}$ ) was filled with Ringer's solution containing 500 $\mu \mathrm{M}$ Fluo-4 AM, 5\% DMSO (v/v), 1\% Pluronic F-127 (w/v), and $500 \mu \mathrm{M}$ MK571 (Alexis Biochemicals). The patch pipette was inserted into the ventral olfactory bulb at the olfactory nerve layer and pushed dorsocaudally into the layer of mitral cells. The dye solution was pressure injected $(50-400 \mathrm{hPa})$ for $1-5 \mathrm{~min}$. The explant preparation was left in Ringer's solution for another $30 \mathrm{~min}$ to allow for uptake and intracellular deesterification of the AM-coupled dye.

Activity correlation imaging and reconstruction of the sensitivity map. Animals were electroporated with Alexa Fluor 647-dextran to reveal the presynaptic glomerular organization. After the whole-mount brain preparation, Fluo-8 AM bolus loading of the neuropil surrounding the $\gamma$-glomerulus was performed, resulting in a postsynaptic $\mathrm{Ca}^{2+}$ staining of the targeted glomerulus and of the mitral cells in its vicinity. $\mathrm{Ca}^{2+}$ measurements were performed with successive applications of cold Ringer's solution or L-histidine (His) with an interstimulus interval of $20-30 \mathrm{~s}$. Brief applications of small volumes of 200-400 $\mu$ l were applied to avoid adaptation of olfactory receptor neurons to the stimuli. The imaging was undertaken with a custom-built line illumination microscope, similar to the one described by Junek et al. (2009), which incorporated two channels for separating the Alexa Fluor 647 and the Fluo-8 AM signals. 3D image stacks were taken with a $63 \times$ water-immersion objective (1.0 NA). Correlation maps were calculated using activity correlation imaging (ACI; Junek et al., 2009). Briefly, we selected two temporal patterns, which exhibited responses to either temperature drops or His stimulation and used them as reference traces, $r(t)$. Then, for every pixel we calculated the cross-correlation with the reference traces, as follows:

$$
c_{i}=\frac{\sum_{n=1}^{N}\left(v_{i}\left(t_{n}\right)-\bar{v}_{i}\right)\left(r\left(t_{n}\right)-\bar{r}\right)}{\left\|v_{i}\left(t_{n}\right)-\bar{v}_{i}\right\| \cdot\left\|r\left(t_{n}\right)-\bar{r}\right\|},
$$

where $v_{i}\left(t_{n}\right)$ denotes the time trace at the $i$ th pixel, and $N$ is the measured number of time points. To determine whether or not a certain region exhibited $\mathrm{Ca}^{2+}$ responses to both negative jumps in temperature, called T-jumps, and L-histidine, we used the following criterion: the response was considered dual sensitive if a pixel showed a higher mean relative change in fluorescence $(\Delta F / F)$ in the $4 \mathrm{~s}$ following stimulus application than its maximum value over the $4 \mathrm{~s}$ before the onset of stimulus application.

Histochemistry after electroporation. Primary olfactory fibers that innervate the $\gamma$-glomerulus and originate from the contralateral olfactory epithelium were traced by inserting a patch pipette filled with Ringer's solution and biocytin into the glomerular layer close to the $\gamma$-glomerulus. After application of square pulses $(100 \mathrm{~V}, 20 \mathrm{~ms}, 20$ pulses at $1 \mathrm{~Hz})$, the pipette was withdrawn. The explant was left in Ringer's solution for $8 \mathrm{~h}$ at room temperature to allow for the retrograde axonal transport of biocytin. Then the tissue was fixed in $4 \%$ PFA (w/v) overnight at $4^{\circ} \mathrm{C}$ and sectioned with a vibratome at $70 \mu \mathrm{m}$. The sections were washed with PBS containing $0.2 \%$ Triton-X (PBST; v/v) for $15 \mathrm{~min}$ and then incubated with Alexa Fluor 488 -avidin conjugate $(100 \mu \mathrm{g} / \mathrm{ml}$ in PBST; Invitrogen) for $2 \mathrm{~h}$ at room temperature. The sections were washed three times for 15 min with PBS, transferred to a solution consisting of $60 \%$ glycerol/PBS, 

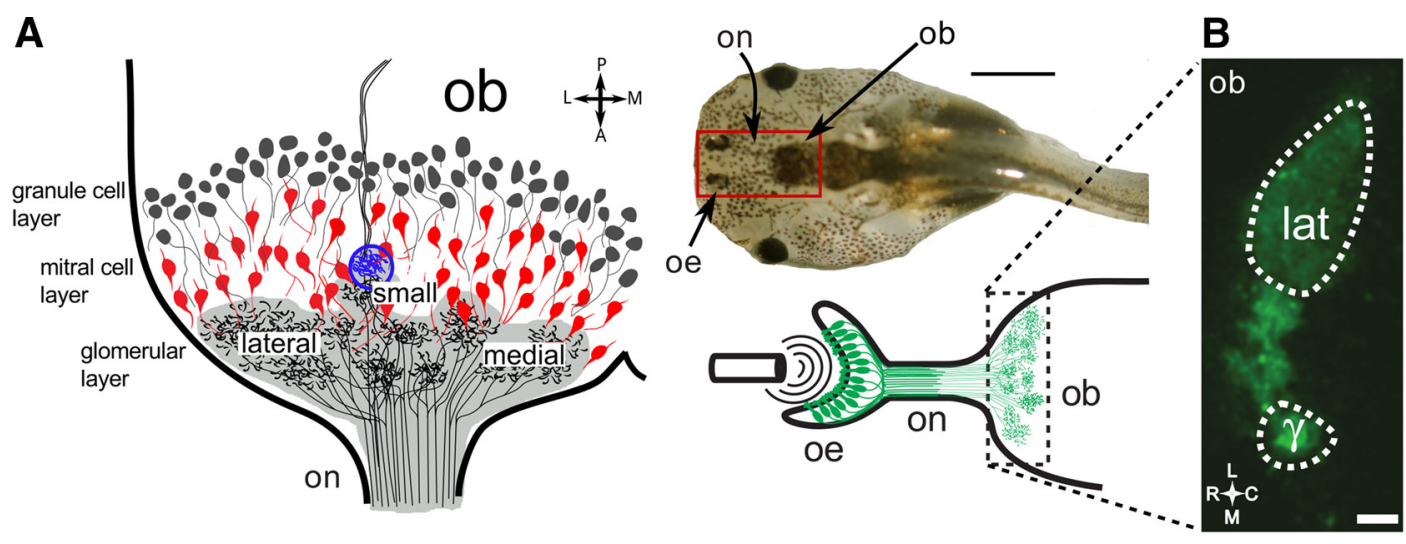

C
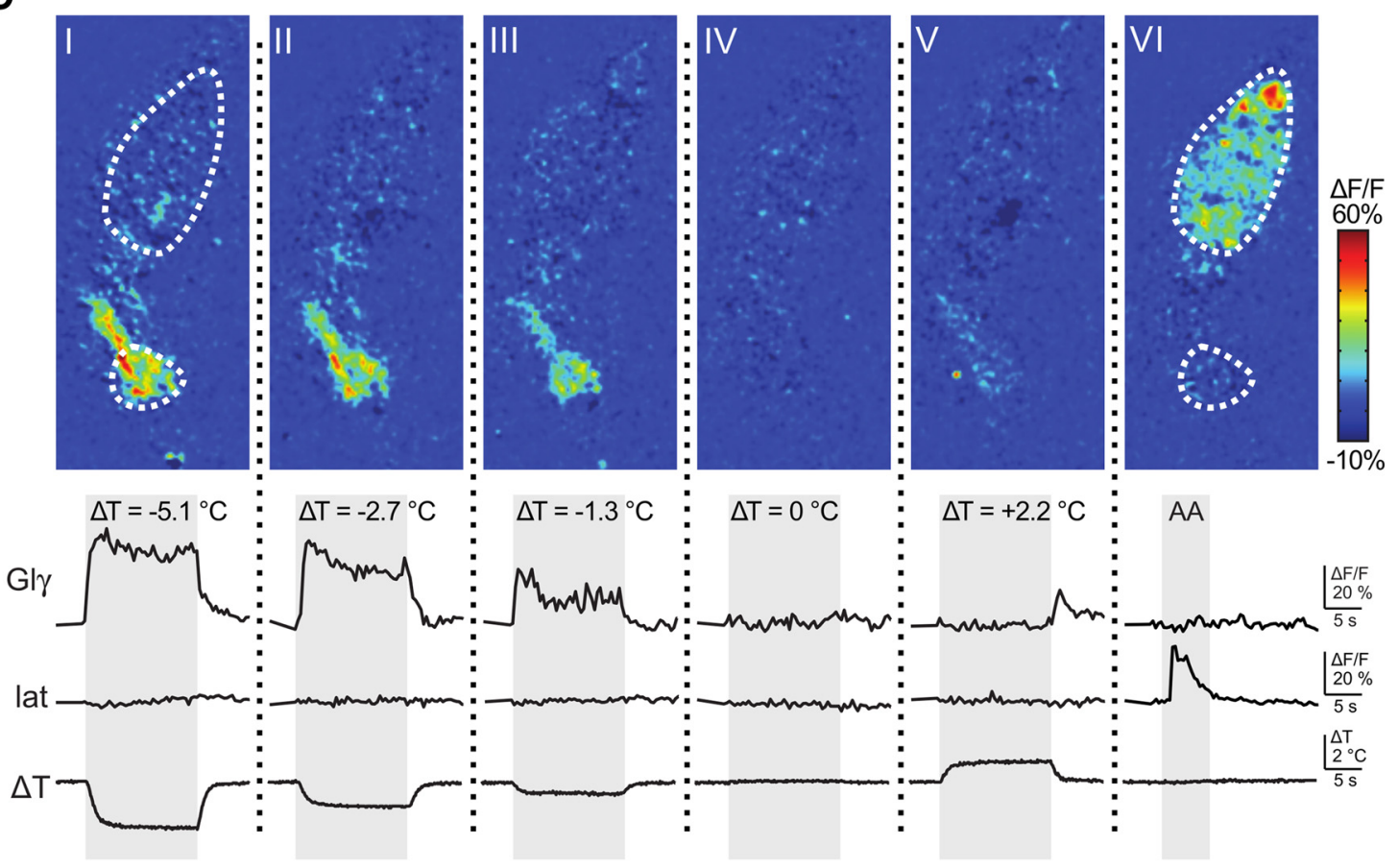

D

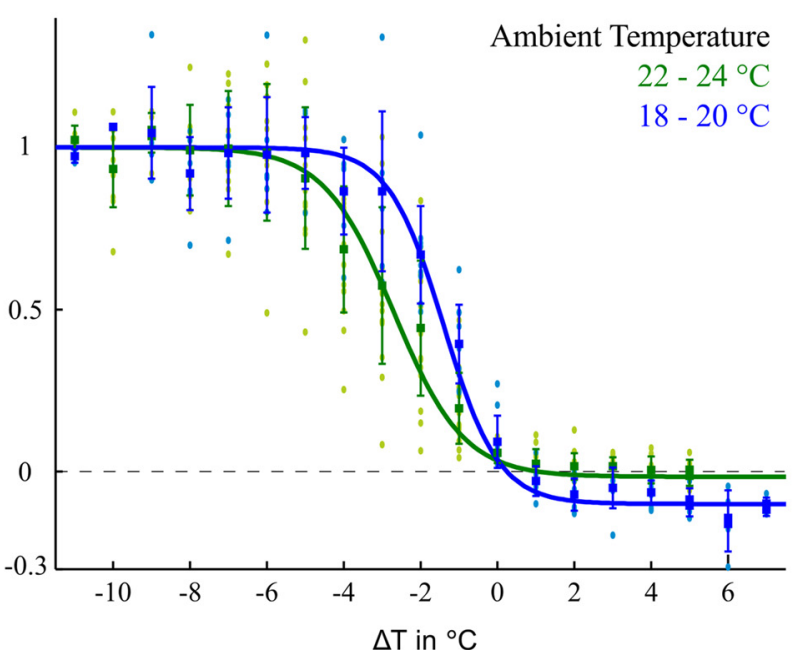

$\mathbf{E}$
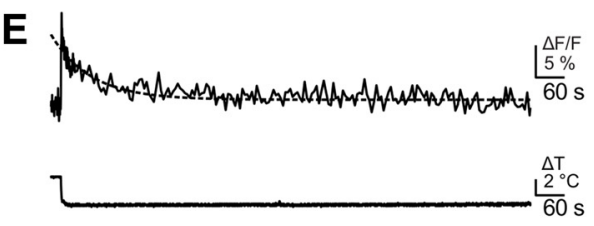

$\mathbf{F}$

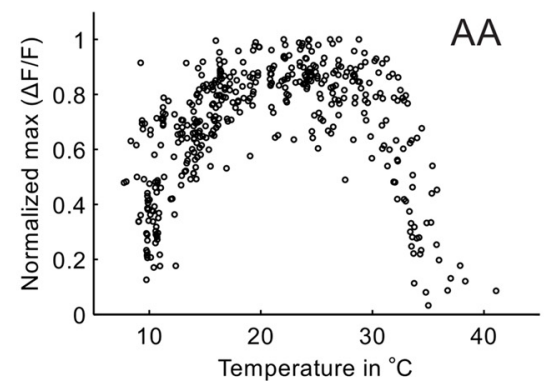

Figure 1. Responses of the $\gamma$-glomerulus upon stimulation. $A$, Overview of the Xenopus olfactory bulb with the different layers and cell types indicated. The positions of the lateral, medial, and small glomerular clusters are labeled. The $\gamma$-glomerulus is situated close to the posterior and ventral border of the glomerular layer within the small cluster and is marked in blue. The top right side shows an image of a tadpole. The red rectangle indicates the area used for sample preparation. Scale bar, $2 \mathrm{~mm}$. On the bottom right side, a scheme of the experiment including the glomerular afferents of the right ventral olfactory bulb is provided. Olfactory sensory neurons electroporated with Fluo-4 dextran are shown in green. $\boldsymbol{B}$, Raw Fluo-4 fluorescence signal before stimulation. $\boldsymbol{C}$, Top, Responses of primary olfactory projections in the ventral olfactory bulb upon stimulation with different temperature changes $(\boldsymbol{I}-\boldsymbol{I V})$ or a mixture of amino acids (VI). The images show the spatial map of the $\Delta F / F$. Bottom, Time courses of responses of the $\gamma$-glomerulus $(\mathrm{Gl} \gamma)$ and glomeruli in the lateral cluster (lat), along with the underlying temperature (Figure legend continues) 
Table 1. List of stimuli applied to the olfactory epithelium

\begin{tabular}{|c|c|c|}
\hline Stimuli & Concentration & Preparations $(n)$ \\
\hline 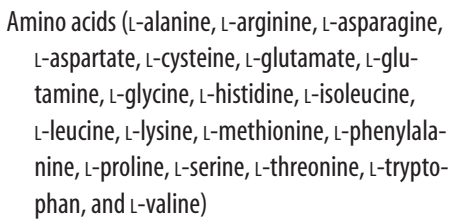 & $200 \mu \mathrm{m}$ each & 20 \\
\hline $\begin{array}{l}\text { Amines (2-phenylethylamine, tyramine, butyl- } \\
\text { amine, cyclohexylamine, hexylamine, 3-meth- } \\
\text { ylbutylamine, N,N-dimethylethylamine, } \\
\text { 2-methylbutylamine, 1-formylpiperidine, } \\
\text { 2-methylpiperidine, N-ethylcyclohexylamine, } \\
\text { 1-ethylpiperidine, and piperidine) }\end{array}$ & $200 \mu$ m each & 7 \\
\hline Taurocholic acid & $200 \mu \mathrm{M}$ & 6 \\
\hline $\begin{array}{l}\text { Nucleotides (adenosine, AMP, ADP, ATP, uridine, } \\
\text { uridine- } 5^{\prime} \text {-triphosphate, cytidine-5' } 5^{\prime} \text {-triphos- } \\
\text { phate, GTP) }\end{array}$ & $100 \mu$ м each & 7 \\
\hline $\begin{array}{l}\text { Alcohols ( } \beta \text {-ionone, citral, } \beta \text {-phenylethyl alcohol } \\
\text { and } \gamma \text {-phenylpropyl alcohol) }\end{array}$ & $200 \mu$ м each & 8 \\
\hline $\begin{array}{l}\text { Pyrazines (pyrazine, 2-methylpyrazine, lutidine, } \\
\text { 2,3-dimethylpyrazine, and 2,5-dimethylpyr- } \\
\text { azine) }\end{array}$ & $100 \mu$ m each & 5 \\
\hline Menthol & $200 \mu \mathrm{M}$ & 3 \\
\hline Forskolin & $50 \mu \mathrm{M}$ & 19 \\
\hline IBMX & $50 \mu \mathrm{M}$ & 5 \\
\hline 8Br-cGMP & $1 \mu \mathrm{M}$ & 4 \\
\hline pH 8.3 & & 6 \\
\hline pH 7.3 & & 6 \\
\hline
\end{tabular}

High concentrations were chosen to ensure that the odor detection threshold of olfactory neurons was crossed. None of these chemicals elicited a response in the $\gamma$-glomerulus.

followed by $80 \%$ glycerol/PBS ( $1 \mathrm{~h}$ each), and finally mounted on glass slides.

Fluorescence imaging with the LSM 510. The nose-brain explant preparation was placed into a recording chamber with its ventral side facing the coverslip. Confocal images were taken using an LSM 510 attached to an Axiovert 100M microscope (Zeiss). Alexa Fluor 488 and Fluo-4 were excited at $488 \mathrm{~nm}$, and Alexa Fluor 568 was excited at $543 \mathrm{~nm}$. The emission was gathered through appropriate long-pass or bandpass filters. Time series were acquired at 1-5 frames/s during stimulus application.

Stimulus application. The stimuli were applied through a custom-built funnel applicator (Schild, 1985), the outlet of which was placed in front of the olfactory epithelium. The stimulus solution was applied either through an electronic pipette (HandyStep electronic, Brandtech Scientific) or solenoid valves (LFRX0500050B, The Lee Company) triggered by a TTL signal synchronized with the experiment. The constant perfusion of the olfactory epithelium with Ringer's solution was not interrupted during the release of the stimulus solution into the funnel.

As temperature stimuli, we used cooled or heated, odor-free, standard Ringer's solution. To monitor the temperature of the solution at the mucosa we used a NiCr-Ni thermocouple (GTF 300, Greisinger Elektronik) placed close to the outlet of the funnel applicator. The measurements were performed either at ambient temperature $\left(22-24^{\circ} \mathrm{C}\right)$ or in

$\leftarrow$

(Figure legend continues.) stimuli $(\Delta T)$, plotted as deviations from ambient temperature. $\boldsymbol{D}$, Summary of normalized temperature response curves of the $\gamma$-glomerulus at two ambient temperatures of $22-24^{\circ} \mathrm{C}$ (green, $n=17$ animals) and $18-20^{\circ} \mathrm{C}$ (blue, $n=9$ animals). The points show the responses of individual animals, and the rectangles indicate the average responses with SD. The sigmoid curves represent the average fit for each ambient temperature. $\boldsymbol{E}$, Representative response of the $\gamma$-glomerulus upon prolonged stimulation (temperature step, $\Delta T=-3.5^{\circ} \mathrm{C}$ ). Dashed line, exponential fit. $\boldsymbol{F}$, Odorant responses of the glomeruli in the lateral cluster as a function of temperature ( $n=5$ animals). $\gamma, \mathrm{Gl} \gamma, \gamma$-glomerulus; ob, olfactory bulb; oe, olfactory epithelium; on, olfactory nerve; lat, lateral cluster; C, caudal; L, lateral; M, medial; $R$, rostral. Scale bar, $20 \mu \mathrm{m}$. cooled Ringer's solution $\left(18-20^{\circ} \mathrm{C}\right)$ that was perfused at least for $15 \mathrm{~min}$ before stimulus application. In graphs or plots, the temperature stimuli are given as $\Delta T=T(t)-T_{0}$, with $T_{0}$ being the temperature monitored at the beginning of each experiment.

Calcium imaging in slices. Horizontal and parasagittal slices of nosebrain preparations that were $150-250 \mu \mathrm{m}$ thick were incubated for $1 \mathrm{~h}$ with a staining solution containing $18 \mu \mathrm{M}$ Fluo-4 $\mathrm{AM}\left(\mathrm{Kd}\right.$ for $\mathrm{Ca}^{2+}=$ $325 \mathrm{nM}$ ) or Fluo-8 AM (Kd for $\mathrm{Ca}^{2+}=389 \mathrm{nM}$ ), 5\% DMSO, 1\% Pluronic F-127, and $50 \mu \mathrm{M}$ MK571. After several washes with pure Ringer's solution, the slice was placed in a recording chamber. Parallel to the Frog's Ringer's perfusion, a mixture of amino acids (L-alanine, L-arginine, L-cysteine, L-histidine, L-isoleucine, L-leucine, L-lysine, L-methionine, L-phenylalanine, L-proline, L-serine, L-threonine, L-tryptophan, and Lvaline; $50 \mu \mathrm{M})$, cool Ringer's solution $\left(0^{\circ} \mathrm{C}\right)$, or room temperature Ringer's solution $\left(20-22^{\circ} \mathrm{C}\right)$ was applied to the nostril, using an electronic pipette controlled by the acquisition software. The temperature drop in the recording chamber was monitored with a $\mathrm{NiCr}-\mathrm{Ni}$ thermocouple placed close to the olfactory epithelium. Each stimulus application was repeated at least twice to ensure reproducibility of the responses. The minimum interstimulus interval was $150 \mathrm{~s}$. The $\left[\mathrm{Ca}^{2+}\right]$ responses of mitral cells were measured using a custom-built line illumination microscope (Junek et al., 2009). 3D volumes were acquired at a rate of 5.5 $\mathrm{Hz} /$ stack with a $40 \times / 0.8 \mathrm{~W}$ water-immersion objective.

Image processing. Image processing was performed with software custom written in MATLAB (MathWorks). Imaged volumes are presented as maximum intensity projections. Stimulation-induced changes in $\left[\mathrm{Ca}^{2+}\right]$ are represented as $\Delta F / F=\left(F(t)-F_{0}\right) /\left(F_{0}\right)$ after subtraction of the background (measured without excitation light). $F_{0}$ represents the average of at least 9 data points preceding the stimulus. For the $\Delta F / F$ traces for regions of interest (ROIs), we first averaged the fluorescence intensities over the pixels of the respective ROI. $\Delta F / F$ spatial maps were low-pass filtered. Odor response amplitudes are represented as peak responses.

Pixel correlation maps were calculated as described previously (Manzini et al., 2007a). Briefly, the fluorescence time course of every pixel was cross-correlated with the fluorescence time courses of its adjacent pixels. The average value of the resulting eight correlation coefficients was then assigned to the central pixel. The image of the averaged correlation factors is referred to as a correlation map. When necessary, shift correction of the measurements was performed with a custom-written MATLAB script. The non-normalized cross-correlation function is as follows:

$$
c_{f, g}(\Delta x, \Delta y)=\iint f(x, y) \cdot g(x+\Delta x, y+\Delta y) d x d y,
$$

which was computed from each consecutive image pair $f(x, y)$ and $g(x, y)$ (average subtracted and zero padded), and was multiplied by a correction factor to compensate for the effect of zero padding. The subpixel coordinates of the maximum of this function was determined by Gaussian fitting and used for shift correction using 2D linear interpolation. In measurements where photo-bleaching was observed, the fluorescence decay of images was corrected by applying a Legendre low-pass filter (Bao and Schild, 2014).

Fitting procedures. Temperature response curves in Figure $1 D$ were fitted with a sigmoidal function using the following formula:

$$
f(x)=a+\frac{b-a}{1+\exp ((c-x) / w)},
$$

with $a-c$ standing for offset, response maximum, and half-maximum temperature changes. The variable $x$ refers to the temperature change, and $w$ is a slope parameter representing the approximate width of the distribution. The fitting was performed in MATLAB (MathWorks) using its nonlinear regression function. After fitting, the temperature response curves were normalized to a constant amplitude. The adaptation of temperature responses was fitted by a monoexponential, yielding the adaptation time constant $\tau$. 
A

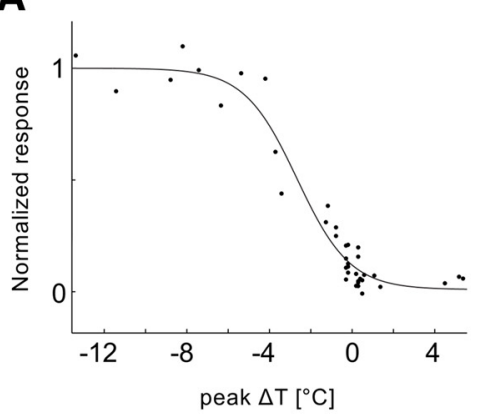

B

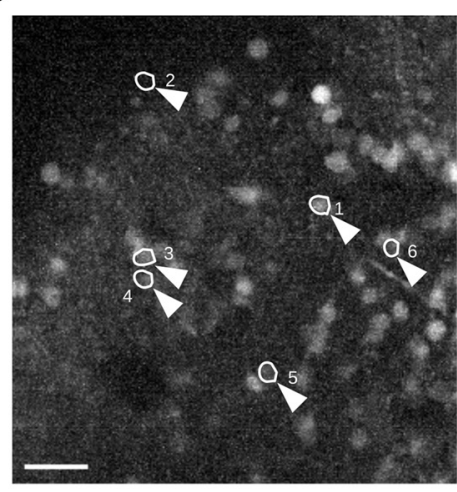

C

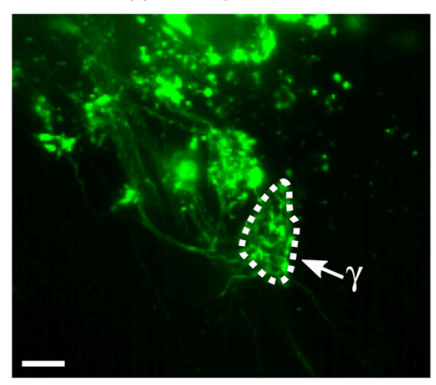

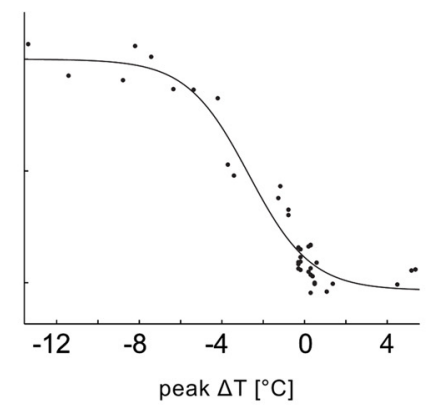

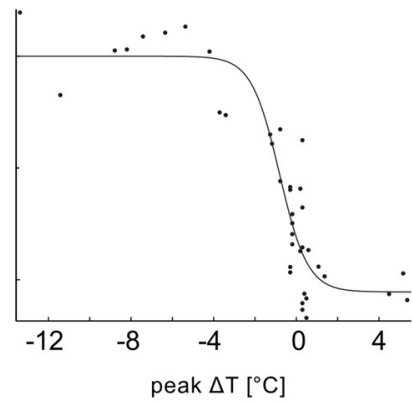

we
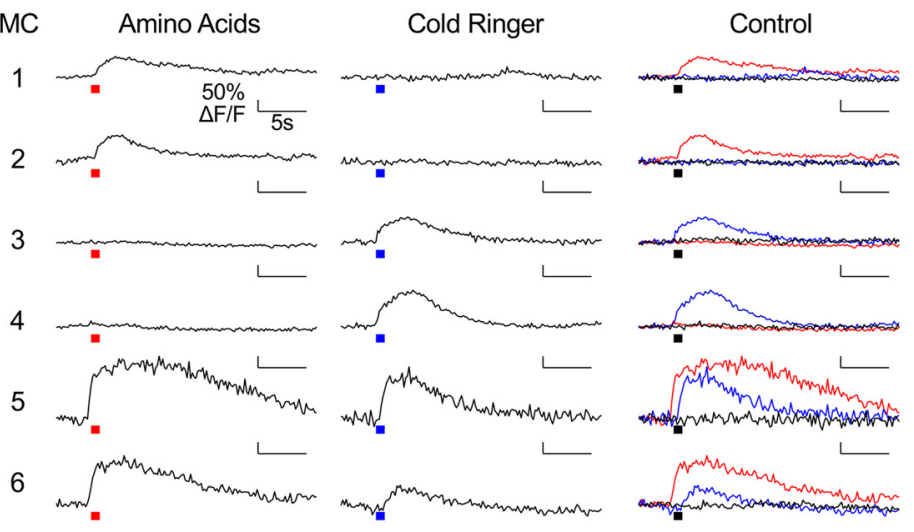

(II) Postsynaptic $\mathrm{ACl}$

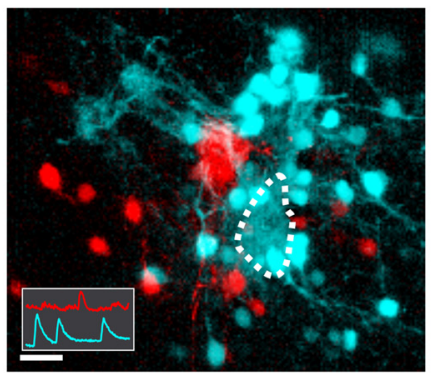

(III) Dual-sensitive

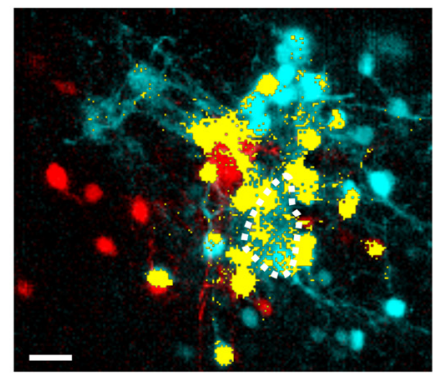

D

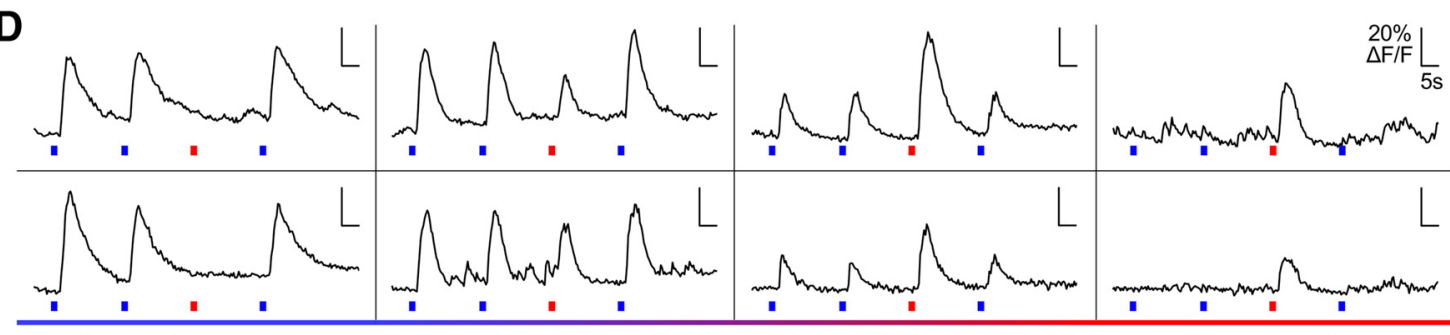

Temperature-sensitive

Temperature- + chemosensitive

Chemosensitive

Figure 2. Temperature sensitivity and chemosensitivity in the olfactory bulb. $A$, Temperature response of the postsynaptic neuropil of a $\gamma$-glomerulus and two mitral cells. Dashed curves, Boltzmann fit. $\boldsymbol{B}$, Integration of temperature and odor sensitivity in individual mitral cells. Left, Maximum projection of a 30- $\mu \mathrm{m}$-thick volume of the olfactory bulb stained with Fluo-4 AM. Arrowheads highlight six mitral cells. Scale bar, $50 \mu \mathrm{m}$. Right, $\mathrm{Ca}^{2+}$ responses of the six mitral cells to a mixture of amino acids, a temperature drop $\left(\Delta T=-1.1^{\circ} \mathrm{C}\right)$, or the control with ambient temperature Ringer's solution. The red and blue bars under the traces indicate the application of amino acids (100 $\mu \mathrm{M})$ and cold Ringer's solution $\left(T=0^{\circ} \mathrm{C}\right)$, respectively. $C$, Response patterns of the small glomerular cluster and surrounding mitral cells to temperature and chemical stimulation. Presynaptic Alexa Fluor staining is shown in green (arrow, $\gamma$-glomerulus; I). Postsynaptic Fluo-8 AM staining was performed through bolus loading. Stimulus sequence: cold Ringer's solution, cold Ringer's solution, L-histidine, cold Ringer's solution. Il, Activity correlation map for the postsynaptic $\mathrm{Ca}^{2+}$ responses. Red, correlation to a pure His response; cyan, correlation to pure temperature drop responses (reference traces as inset). III, Regions responding to both stimuli (yellow). All images are maximum projections of the same $36-\mu \mathrm{m}$-thick volume. Scale bar, $20 \mu \mathrm{m} . \boldsymbol{D}, \Delta F / F$ traces representing different mitral cells from the measurement in $\boldsymbol{C}$. The relative response strength ranges from pure thermosensitivity to exclusive histidine sensitivity over various degrees of dual sensitivity. The bars under the traces depict the stimulus application in the same manner as in $\boldsymbol{B}$.

\section{Results}

Temperature sensitivity in the $\gamma$-glomerulus

We used a nose-brain preparation to study the sensory input of the olfactory bulb upon natural stimulation of the olfactory epithelium (Fig. 1A,B). Fluo-4 conjugated to a $10 \mathrm{kDa}$ dextran served as the reporter dye. Situated between the lateral cluster, which is sensitive to amino acid odorants (Fig. $1 C_{V I}$ ), and the medial cluster, which is sensitive to alcohols, are two clusters, the 


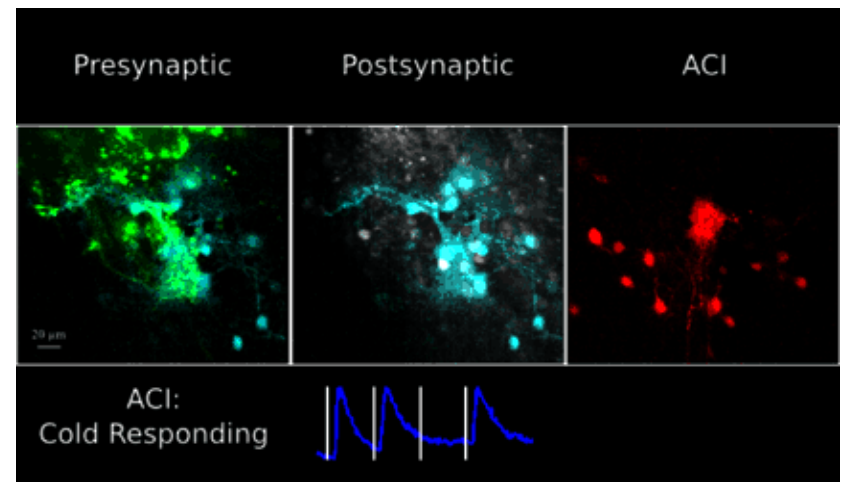

Movie 1. Postsynaptic combination of temperature sensitivity and chemosensitivity. First, the movie shows a measurement of the small cluster where the presynaptic side is stained with Alexa Fluor 647, shown here in green. Overlaid is a $\Delta F / F$ map for the postsynaptic side, which was stained with Fluo-8 AM dye through bolus loading. Four regions of interest corresponding to different mitral cells were selected whose response traces are shown on the right side. Each response trace was normalized individually to its maximum. Next, four consecutive stimulations with an interstimulus interval of $20 \mathrm{~s}$ are visualized in this sequence: two applications of cold Ringer's solution followed by one stimulation with His (10 $\mu \mathrm{m})$ and a final application of cold Ringer's solution. The images are maximum projections of a $36-\mu$ m-thick region. The second part of the movie shows 3D ACl maps overlaid to maximum projections of presynaptic and postsynaptic staining of the small cluster. The last frames indicate dual-sensitive regions of interest in a maximum projection of $\mathrm{ACl}$ maps.

intermediate and small clusters whose functions have so far remained unclear. Here we focus on the $\gamma$-glomerulus, which responded to none of the odorants so far known to be effective in $X$. laevis tadpoles (Table 1). However, cooled standard Ringer's solution, when applied as a stimulus to the olfactory epithelium, reproducibly induced an increase in $\left[\mathrm{Ca}^{2+}\right]$ in the primary afferents of the $\gamma$-glomerulus (Fig. $1 C_{I-I V}$ ). This neuropil, which together with the $\beta$ - and $\delta$-glomeruli builds the small cluster, was easily identifiable across brain preparations because of its isolated location and ventroposterior position in the glomerular layer. The changes in $\left[\mathrm{Ca}^{2+}\right]$ induced by $\mathrm{T}$-jumps gradually increased with increasing amplitude of the temperature jump (Fig. $\left.1 C_{I-I V}\right)$. Responses to T-jumps showed a fast onset (Fig. $1 C_{I-I V}$, bottom panels) and slow adaptation $(\tau=160 \pm 80 \mathrm{~s}$, mean $\pm \mathrm{SD} ; n=5$ animals; Fig. 1E). The glomeruli of the lateral cluster, which are sensitive to amino acid stimuli, were not affected by $\mathrm{T}$-jumps (Fig. $1 C_{I-V}$ ). Positive T-jumps did not induce fluorescence increases in the $\gamma$-glomerulus. Due to the adaptation of the system, however, an off-response occurred when stepping back from an elevated temperature level to ambient temperature $\left(22-24^{\circ} \mathrm{C}\right.$; Fig. $\left.1 C_{V}\right)$. It was rather unexpected that a decrease in temperature triggered an increase of the $\left[\mathrm{Ca}^{2+}\right]$ signal, since odor responses in Xenopus OSNs are approximately temperature independent, at least over a wide range $\left(17-28^{\circ} \mathrm{C}\right)$, and they decrease only beyond this range (Fig. $1 F ; n=5$ animals). The responses to negative $\mathrm{T}$-jumps of the presynaptic $\left[\mathrm{Ca}^{2+}\right]$ signals in $\gamma$-glomeruli were fitted with a sigmoidal function as a model for a typical doseresponse curve (Fig. $1 D$, green line; $n=17$ animals). The fit gave the average data distribution and was used to determine the position of the half-maximal response at $\Delta T_{1 / 2}=-2.7 \pm 1.1^{\circ} \mathrm{C}$. The temperature sensitivity at this point, in terms of relative fluorescence change, was $23 \pm 6 \% /{ }^{\circ} \mathrm{C}$. To evaluate whether $\gamma$-glomerulus responses were altered by a change of ambient temperature, brain preparations were perfused with cooled Ringer's solution $\left(18-20^{\circ} \mathrm{C}\right)$ for at least $15 \mathrm{~min}$ to allow adaptation to the new temperature (Fig. 1E). Subsequently, brief temperature changes were again applied to the nose (Fig. $1 D$, blue line; $n=9$ animals). The responses to $\mathrm{T}$-jumps at a lower ambient temperature were half-maximal at $\Delta T_{1 / 2}=-1.4 \pm 0.7^{\circ} \mathrm{C}$, and the temperature sensitivity at this point was $38 \pm 8 \% /{ }^{\circ} \mathrm{C}$. As the observed temperature sensitivity of the $\gamma$-glomerulus might have been brought about by temperature-induced $\mathrm{pH}$ changes of the HEPES-buffered Ringer's solution, we performed control experiments, which excluded such an indirect effect (Table 1).

\section{Integration of thermosensitive and chemosensitive inputs}

To see whether the T-jump-induced presynaptic activity of the $\gamma$-glomerulus was conveyed to mitral cells, we stained all neurons of the olfactory bulb with Fluo-4 AM ester by bulk loading (Stosiek et al., 2003; Junek et al., 2010). We applied stimuli in the range between $5^{\circ} \mathrm{C}$ and $-14^{\circ} \mathrm{C}$ to the epithelium and imaged the olfactory bulb. Representative temperature response curves are plotted for the $\gamma$-glomerulus (postsynaptic neuropil) and two mitral cells measured during the same experiment (Fig. 2A). Clearly, both the glomerulus and the mitral cells responded in a graded manner to the temperature changes applied. The sensitivities proved to be similar to those observed in the presynaptic afferents, with $24 \pm 5 \% /{ }^{\circ} \mathrm{C}$ at $\Delta T_{1 / 2}=-2.5 \pm 0.4^{\circ} \mathrm{C}$ in the region of the $\gamma$-glomerulus and $24 \pm 10 \% /{ }^{\circ} \mathrm{C}$ at $\Delta T_{1 / 2}=-2.5 \pm 1.6^{\circ} \mathrm{C}$ in mitral cell somata ( $n=5$ animals, 39 cells).

These results suggest that temperature sensitivity is processed in X. laevis mitral cells. Since mitral cell networks have been investigated mostly for the encoding of chemosensation, we subsequently examined whether a combined processing of odors and temperature occurs in the same mitral cells of the main olfactory bulb. Using a $40 \times$ objective ( $0.8 \mathrm{NA}$ ) allowed us to simultaneously observe dozens of mitral cells in olfactory bulb slices. They were screened for temperature sensitivity and chemosensitivity by measuring their $\mathrm{Ca}^{2+}$ responses to the application of cold Ringer's solution, which caused a temperature drop of $-1.1^{\circ} \mathrm{C}$ on average, and a mixture of amino acids (for details, see Material and Methods) at a concentration of $50 \mu \mathrm{M}$ each (Fig. 2B). Room temperature Ringer's solution was used as a negative control. We observed reversible $\Delta F / F$ peak responses of mitral cell somata induced by amino acid stimulation or small temperature drops. These mitral cells thus possessed a dual sensitivity, responding to both stimuli, albeit not with the same $\Delta F / F$. In these recordings, the field of view $(366 \times 450 \times 40 \mu \mathrm{m})$ was sufficiently large to comprise the lateral glomerular cluster where calcium responses to amino acids were most frequently observed, as well as the $\gamma$-glomerulus. One hundred fifty-one of 183 cells ( $n=9$ animals) were amino acid sensitive only, 13 were exclusively cold sensitive, and 19 showed dual responses to both stimuli. Overall, 19 of 32 thermosensitive mitral cells (59\%) were also chemosensitive.

To further confirm this finding, we proceeded to a detailed analysis of the dual-sensitive cells in the close vicinity of the $\gamma$-glomerulus (Movie 1). We used a whole-mount brain preparation where the glomeruli were stained by electroporation of the olfactory epithelium with Alexa Fluor 647-dextran, allowing the precise localization of the small cluster comprising the $\beta-, \gamma-$, and $\delta$-glomeruli. In addition, Fluo- 8 AM bolus loading of the neuropil surrounding the $\gamma$-glomerulus was performed, resulting in postsynaptic $\mathrm{Ca}^{2+}$ dye staining of the targeted glomerulus and of the mitral cells in its vicinity (Fig. 2C). Successive applications of cold Ringer's solution were followed by the administration of the single amino acid L-histidine at a concentration of $10 \mu \mathrm{M}$. We applied ACI (Junek et al., 2009) to reveal the somata and neurites of all cells showing temporally correlated $\mathrm{Ca}^{2+}$ signals, using the responses of a purely temperature-sensitive or a purely histidine- 

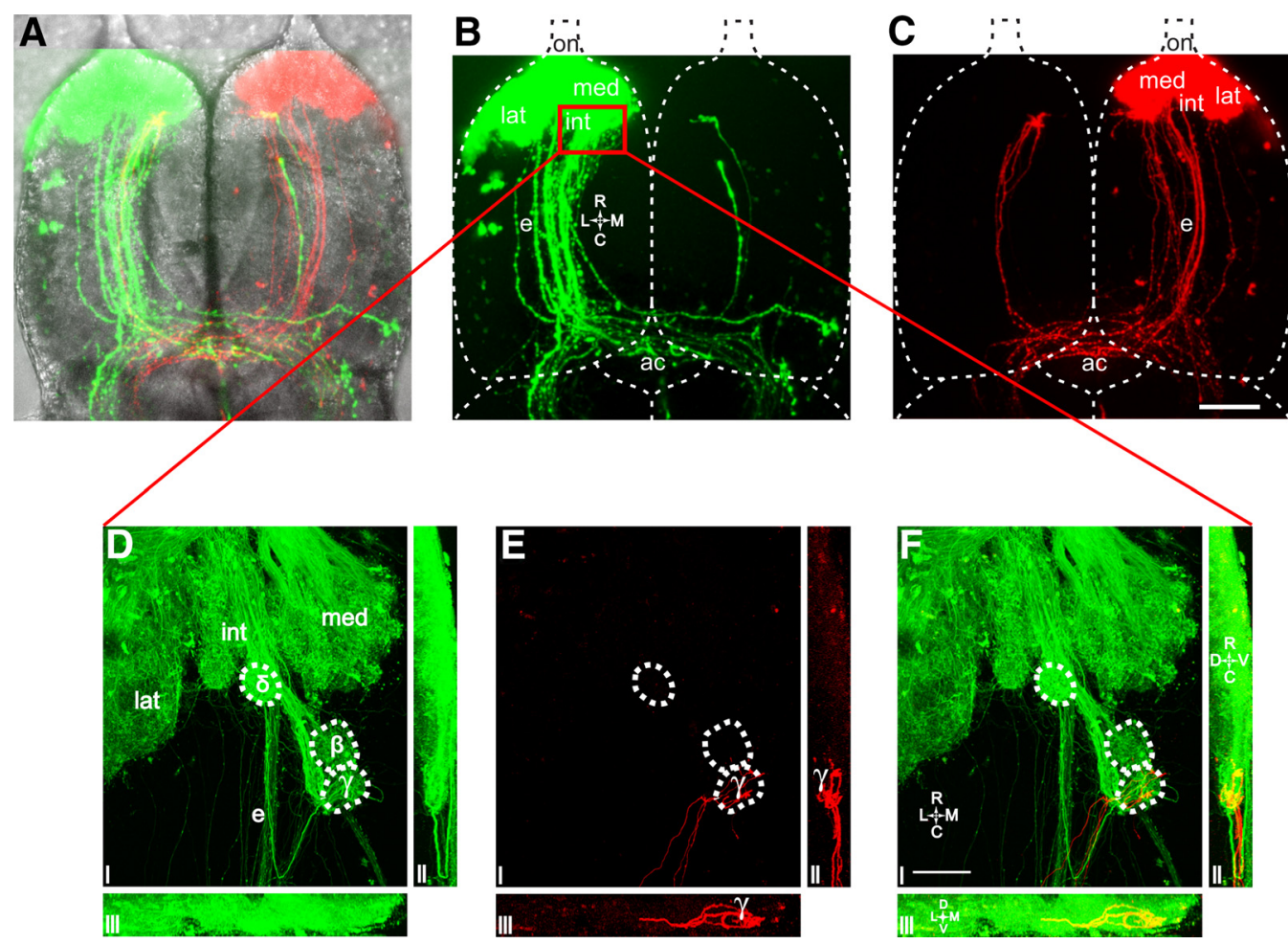

Figure 3. Bilateral projections of OSN axons. Maximum intensity projection along the dorsoventral axis of a $128-\mu \mathrm{m}$-thick volume within the ventral olfactory bulb. $\boldsymbol{A}-\boldsymbol{C}$, Primary olfactory projections $(\boldsymbol{A})$ from the left (green, $\boldsymbol{B}$ ) and right (red, $\boldsymbol{C}$ ) olfactory epithelium, overlaid with a widefield image of the same preparation (gray). ac, Anterior commissure; e, extrabulbar olfactory fibers; on, olfactory nerve; med, medial cluster; int, intermediate cluster; lat, lateral cluster; C, caudal; L, lateral; M, medial; R, rostral. Scale bar, $100 \mu \mathrm{m}$. $\boldsymbol{D}-\boldsymbol{F}$, Innervation of the $\gamma$-glomerulus by contralateral OSN axons. D, The imaged volume is presented in three maximum intensity projections (dorsoventral, I; mediolateral, II; rostrocaudal, III). $\boldsymbol{E}$, OSN axons emerging from the left, ipsilateral olfactory epithelium are presented in green; and OSN axons from the right, contralateral olfactory epithelium in red. $\boldsymbol{F}$, Overlay of the fluorescence images in $\boldsymbol{D}$ and $\boldsymbol{E}$. $\beta, \beta$-Glomeruli; $\gamma, \gamma$-glomeruli; $\delta, \delta$-glomeruli; $\mathrm{e}$, extrabulbar olfactory fibers; med, medial cluster; int, intermediate cluster; lat, lateral cluster; $C$, caudal; L, lateral; M, medial; R, rostral; $;$, ventral; D, dorsal. Scale bar, $50 \mu$ m.

sensitive cell as reference signals. ACI maps revealed two glomeruli identified as the $\gamma$-glomerulus and a neighboring glomerulus highly sensitive to L-histidine, as well as the mitral cells exhibiting correlated response patterns inherent to the encoding of thermosensation (Fig. $2 C_{I I}$, blue) or chemosensation (Fig. $2 C_{I I}$, red). Most cold-sensitive regions showed fibers projecting to the $\gamma$-glomerulus or colocalized with presynaptic afferents innervating the $\gamma$-glomerulus (Fig. $2 C_{I, I I}$ ). In addition, we identified dualsensitive cells on a pixel-by-pixel basis. If a pixel showed, within $4 \mathrm{~s}$ after stimulus onset, a mean $\Delta F / F$ higher than the maximum intensity value in the $4 \mathrm{~s}$ preceding the stimulus for both conditions, it was considered a dual-sensitive region and was color coded as such (Fig. $2 C_{I I I}$ ). Note that Figure $2 C$ shows maximum projections of a 36- $\mu \mathrm{m}$-thick volume, while all calculations were computed on the individual $z$-layers. The response patterns of most mitral cells in the imaging volume fell into the following three categories: odor sensitivity, thermosensitivity, or dual sensitivity (Fig. 2D). Interestingly, the latter group comprised cells that reacted stronger to temperature drops than to L-histidine, and vice versa. These dual-responsive cells were thus differentially tuned to temperature and odorants. From these experiments, we conclude that there is an effective integration of thermosensitive and chemosensitive inputs in the olfactory bulb.

\section{Afferent innervation pattern of the $\boldsymbol{\gamma}$-glomerulus}

In the above, we were able to stain a temperature-responsive glomerulus by electroporation of the olfactory mucosa, suggesting the presence of thermosensory neurons in the olfactory epithelium. In other species, specifically in rodents, the niche of thermosensors lies in the GG (Mamasuew et al., 2008; Brechbühl et al., 2014). This organ is quite distinct from the main olfactory epithelium, and the axons of GG neurons project to the necklace glomeruli of the olfactory bulb (Fuss et al., 2005). Intrigued by this difference, we further investigated the innervation pattern of this cold-sensing neuropil. The glomeruli of the olfactory bulb were visualized using dextran-conjugated fluorophores. After electroporation of the olfactory epithelia with Alexa Fluor 488 (10 $\mathrm{kDa}$ dextran, left olfactory epithelium) and Alexa Fluor 568 (10 $\mathrm{kDa}$ dextran, right olfactory epithelium), the glomerular layer of each bulb became heavily stained with the respective dye (Fig. $3 A$ ). Figure 3 shows an overlay of the corresponding wide-field image to indicate the contours of the olfactory nerves and the brain. While most fibers terminate at their glomerular targets, a small subset of fibers cross the glomerular layer, and in fact the olfactory bulb, and run to the anterior commissure, from where they project bilaterally as extrabulbar olfactory fibers to higher brain centers (Pinelli et al., 2004; Fig. 3A-C). In addition, and quite unexpectedly, given the lack of precedent, some of the fibers crossing the anterior commissure clearly project back into the glomerular layer of the contralateral olfactory bulb, thereby giving rise to a double-stained structure (Fig. $3 A$, yellow).

Imaging the very ventral part of the olfactory bulb at higher resolution (Fig. 3D) clearly revealed the $\beta$-, $\gamma$-, and $\delta$-glomeruli as defined by Gaudin and Gascuel (2005), Figure 3D, II and III, showing the $x$ - and the $y$-projections of the imaged volume. The primary afferent fibers (red) entering from the contralateral side project to the region of the $\gamma$-glomerulus (Fig. $3 E$ ). The overlay of the ipsilateral and contralateral projections (Fig. $3 F$ ) allows the unambiguous identification of the $\gamma$-glomerulus, which receives input from both sides. Contralaterally, projecting fibers occa- 

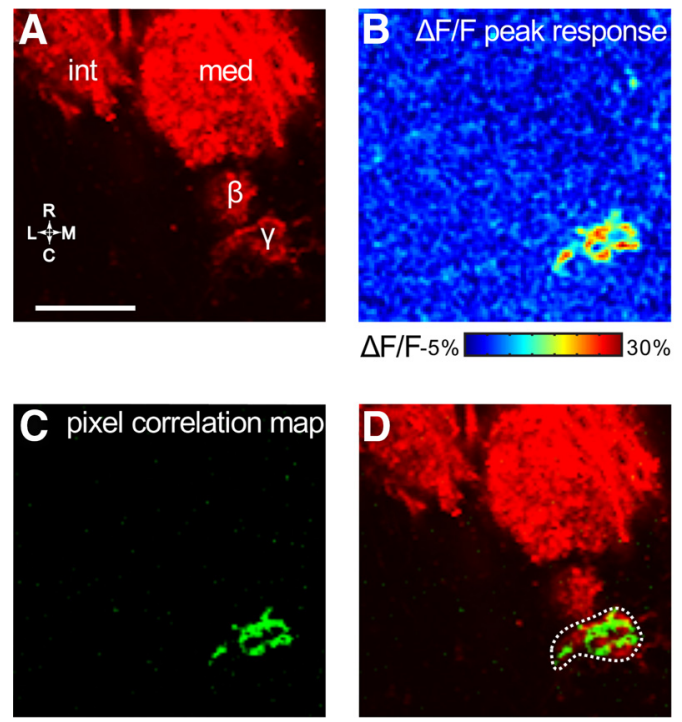

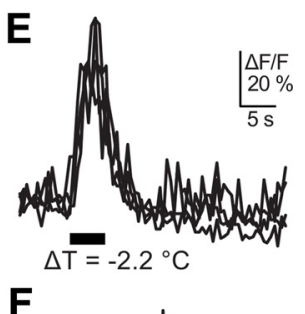

$\mathbf{F}$

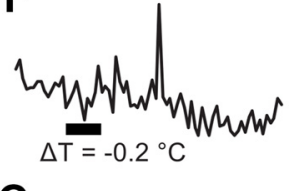

G

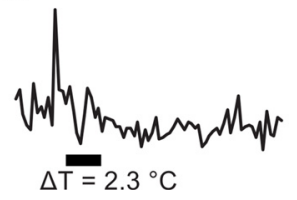

Figure 4. Temperature sensitivity of the contralateral OSN glomerular afferents. $A$, Primary ipsilateral olfactory projections of the medioventral olfactory bulb, traced with Alexa Fluor 568. $B$, Peak response $(\Delta F / F)$ of a single stimulation $\left(\Delta T=-2.5^{\circ} \mathrm{C}\right) . \boldsymbol{C}$, Pixel correlation map of a single response upon a stimulation $\left(\Delta T=-2.5^{\circ} \mathrm{C}\right)$ at the contralateral olfactory epithelium. $D, 0$ verlay of $\boldsymbol{A}$ and $\boldsymbol{C}$. The ROl used to compute response traces plotted in $\boldsymbol{E}-\boldsymbol{G}$ is marked by a dotted line. $\boldsymbol{E}-\boldsymbol{G}$, Temperature responses $(\Delta F / F)$ obtained from the $\gamma$-glomerulus encircled in $\boldsymbol{D}$. Applied stimuli: $\boldsymbol{E}, \Delta T=-2.2 \pm 0.5^{\circ} \mathrm{C} ; \boldsymbol{F}, \Delta T=-0.2^{\circ} \mathrm{C} ; \boldsymbol{G}, \Delta T=+2.3^{\circ} \mathrm{C}$. The black bar under the trace shows the length of the stimulus application. Scale bar, $50 \mu \mathrm{m}$.

sionally wandered to an area rostral to the $\gamma$-glomerulus but did not appear to aggregate there (Fig. 3B). To identify the origin of the contralateral afferents to the $\gamma$-glomerulus, we electroporated biocytin into the neuropil surrounding this glomerulus. The subsequent counterstain with Alexa Fluor 488-avidin revealed a large number of ipsilateral fibers, both afferents and mitral cells, but also contralateral afferents. In fact, the avidin-stained cells in the contralateral olfactory epithelium have the characteristic shape of OSNs.

\section{Bilateral temperature sensitivity of the $\gamma$-glomerulus and mitral cells}

To determine whether the contralateral innervation of the $\gamma$-glomerulus contributed to its responses, we stained the afferents of the ipsilateral (left) olfactory epithelium using Alexa Fluor 568 dextran (Fig. 4A) and those of the contralateral (right) olfactory epithelium using Fluo-4 $10 \mathrm{kDa}$ dextran ( $n=8$ animals). Negative T-jumps applied to the contralateral olfactory epithelium clearly increased the fluorescence signals in the ipsilateral $\gamma$-glomerulus (Fig. 4B,E). The responsive pixels, as revealed by their correlation map (Fig. 4C), perfectly overlapped with the $\gamma$-glomerulus (Fig. 4D). Application of Ringer's solution at room temperature (Fig. $4 F$ ) or of warmed Ringer's solution (Fig. 4G) did not elicit any response. Consequently, the contralateral innervation of the $\gamma$-glomerulus is functional, thus ensuring that the $\gamma$-glomerulus receives thermosensory information from both nasal cavities.

Finally, we tested the role of the contralateral innervation on thermosensation processing in mitral cell networks. Olfactory receptor neurons in the contralateral (right) nasal cavity were electroporated with Alexa Fluor 568 dextran. A number of stained fibers ran through the contralateral olfactory bulb, reached and crossed the anterior commissure, and then backprojected to the ipsilateral (left) olfactory bulb, highlighting the $\gamma$-glomerulus presynaptically (Fig. 5A). Mitral cell somata and their dendrites were bulk stained by Fluo-4 AM, and the ipsilateral (left) bulb was imaged. The net uptake of Fluo-4 AM into temperature drop (Fig. 5G). In both experiments, the field of view comprising the $\gamma$-glomerulus typically contained $7.4 \pm 1.9$ temperature-sensitive mitral cells (Fig. 5D, G, arrowheads). This final set of results strongly demonstrates that both ipsilateral and contralateral afferents convey to the $\gamma$-glomerulus temperaturesensitive information, which is relayed to mitral cells for further processing.

\section{Discussion}

This article exposes novel findings on the encoding of thermosensation in the olfactory bulb of $X$. laevis. First, the $\gamma$-glomerulus, morphologically identified by Gaudin and Gascuel (2005) for the first time in these animals, responds to cool solutions applied to the olfactory epithelium rather than to odorants. Second, temperature information is relayed to postsynaptic mitral cells. The existence of numerous dual-sensitive cells with various degrees of specialization indicates a combined processing and coding of temperature and chemical stimulation in the olfactory system. Third, the $\gamma$-glomerulus is not only innervated by ipsilateral afferents, but also by contralateral fibers crossing the anterior commissure.

Temperature-sensitive glomeruli in the olfactory bulb have not been previously described. However, as neurons of the Grueneberg ganglion of the mouse respond to cool temperatures (Mamasuew et al., 2008; Schmid et al., 2010) and project to the necklace glomeruli in the olfactory bulb (Fuss et al., 2005; Koos and Fraser, 2005; Fleischer et al., 2006; Roppolo et al., 2006; Storan and Key, 2006), the necklace glomeruli are excellent candidates for being temperature-sensitive. Another parallel between the necklace glomeruli and the $\gamma$-glomerulus may be their respective positions. Both appear in specific clusters, the former on the caudal rim of the mouse olfactory bulb (Shinoda et al., 1989) and the latter at the very ventrocaudal pole of the Xenopus olfactory bulb (Gaudin and Gascuel, 2005).

The dynamic range of temperature responses of the $\gamma$-glomerulus is $5.4^{\circ} \mathrm{C}$, over which $\mathrm{T}$-jump responses increase 
A
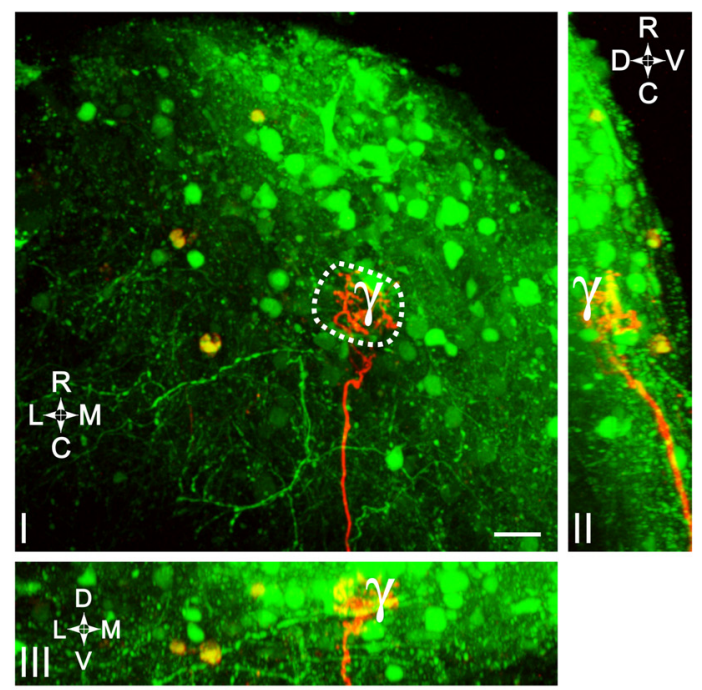

B

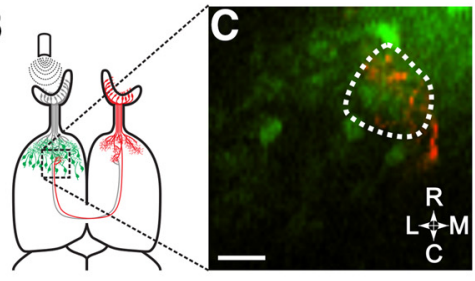

E

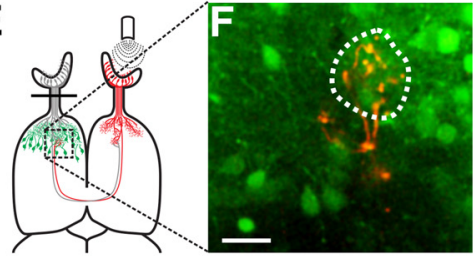

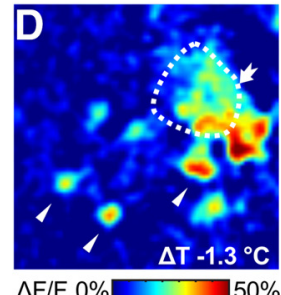

$\Delta \mathrm{F} / \mathrm{F} 0 \% \square$

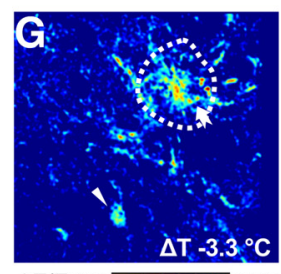

$\Delta \mathrm{F} / \mathrm{F} 0 \%$
Figure 5. Postsynaptic response of a $\gamma$-glomerulus upon temperature stimulation in the olfactory epithelium. $\boldsymbol{A}$, Maximum intensity projections (dorsoventral, $\boldsymbol{I}$; mediolateral, II; rostrocaudal, III) of the ventral olfactory bulb after bolus injection of Fluo-4 AM (green). OSN axons originating from the contralateral olfactory epithelium (red, Alexa Fluor 568) enter the imaged volume at the ventrocaudal rim, protrude rostrodorsally (II) and form a glomerular tuft in the region of the $\gamma$-glomerulus. $\boldsymbol{B}$, Stimulation $\left(\Delta T=-1.3^{\circ} \mathrm{C}\right)$ at the ipsilateral olfactory epithelium. $C$, The contralaterally projecting fibers indicate the region of the $\gamma$-glomerulus. $D, \Delta F / F$ peak response of postsynaptic elements upon cold stimulus occurs in the same region. Arrow, Neuropil; arrowheads, mitral cells. $\boldsymbol{E}-\boldsymbol{G}$, Stimulation $\left(\Delta T=-3.3^{\circ} \mathrm{C}\right)$ at the contralateral olfactory epithelium of the same brain preparation. The ipsilateral nerve was cut $(\boldsymbol{E})$. $\boldsymbol{F}$, The contralaterally projecting fibers indicate the region of the $\gamma$-glomerulus. $G, \Delta F / F$ peak response of postsynaptic elements upon cold stimulus occurs in the same region. Arrow, Neuropil; arrowhead, mitral cell; $\gamma, \gamma$-glomerulus. Scale bars, $20 \mu \mathrm{m}$.

from $5 \%$ to $95 \%$ of the maximum effect. In comparison, the dynamic ranges of the Grueneberg ganglion and TRPM8 are $\sim 10^{\circ} \mathrm{C}$ (Schmid et al., 2010) and $20^{\circ} \mathrm{C}$ respectively (Myers et al., 2009). The sensory afferents to the $\gamma$-glomerulus are thus endowed with an extraordinarily high sensitivity, which is presumably not mediated by TRPM8 receptors. This is further supported by the finding that the $\gamma$-glomerulus remains unaffected by the application of menthol to the epithelium (Table 1 ), just as was found in the Grueneberg ganglion (Schmid et al., 2010).

In mice, GG neurons constitute a separate olfactory subsystem, distinct from the main olfactory epithelium. These cells send their axons to necklace glomeruli in the bulb. Besides, some necklace glomeruli receive sensory input from guanylyl cyclase type D (GC-D) cells in the main olfactory epithelium (Juilfs et al., 1997; Leinders-Zufall et al., 2007; Cockerham et al., 2009). In Xenopus tadpoles, the thermosensitive cells projecting to the $\gamma$-glomerulus are olfactory receptor neurons located in the main olfactory epithelium. Given their position, one could speculate that these cells might be sensitive to both temperature and odorants. However, none of the odorants that we applied triggered a response in the $\gamma$-glomerulus, dimethylpyrazine included, which has been recently reported to modulate the thermosensitive GG neurons (Mamasuew et al., 2011). Of course, this does not eliminate the possibility for an has-yet-to-be discovered chemical stimulus activating the $\gamma$-glomerulus. While a cGMP cascade is discussed to be a part of the transduction process in the Grueneberg ganglion (Liu et al., 2009; Mamasuew et al., 2010; Schmid et al., 2010), the temperaturesensitive neurons innervating the $\gamma$-glomerulus were not sensitive either to $8 \mathrm{Br}$-cGMP or IBMX, indicating a different transduction pathway (Table 1). Contrary to the Grueneberg ganglion, the $\gamma$-glomerulus shows relatively fast adaptation to ambient temperatures (Fig. $1 E$ ), possibly owing to the fact that Xenopus is a poikilotherm.

Our data provide evidence that the thermosensory information collected in both nasal cavities is conveyed across glomerular synapses to mitral cells for further processing in olfactory bulb networks. Ramón y Cajal (1995) described interbulbar communication from tufted cells to contralateral interneurons, yet a contralateral innervation of glomeruli via the anterior commissure as described herein for primary olfactory fibers had not been shown. Evidence of contralateral glomerular innervation by afferent fibers crossing the midline between left and right bulbs came from later studies (Ebbesson et al., 1986; Byrd and Burd, 1991; Gaudin and Gascuel, 2005; Nezlin and Schild, 2005). However, the interbulbar projections observed never crossed caudally to the glomerular layer. The novelty reported in the current study lies in the double innervation of a specialized neuropil by ipsilateral and contralateral afferents conducting olfactory input of the same quality, namely thermosensation. The obvious difference between the ipsilateral and contralateral afferent paths is the length difference of axons, which amounts to $\sim 1 \mathrm{~mm}$ at stage 47. This corresponds to a delay of $\sim 7 \mathrm{~ms}$, assuming a spike propagation velocity of $0.14 \mathrm{~m} / \mathrm{s}$, as in the frog olfactory nerve (Ottoson, 1959). However, these values change with the growth of the animal and its brain in particular. A negative T-jump applied at precisely the same time to both epithelia would activate both $\gamma$-glomeruli, with each receiving a direct and early input via the ipsilateral afferents, and an indirect and slightly delayed input via the anterior commissure. More often, though, a temperature front would hit the mucosae sequentially rather than simultaneously, the delay between left and right signals potentially telling the angle between the animal and the cold front. The $\gamma$-glomerulus might detect such delays for the spatial localization of the thermal stimuli. Such an assumption is supported by literature reporting that differences in odor concentration or in time delays of stimulus detection between the two nostrils underpin the spatial mapping of olfactory stimuli, as reported for humans (von Békésy, 1964; Porter et al., 2005), moles (Catania, 2013), rats (Rajan et al., 2006), sharks (Gardiner and Atema, 2010), and flies (Duistermars et al., 2009). Bilateral innervation of glomeruli by olfactory receptor neurons might underlie the integration of olfactory information from bilateral receptive fields. It will be intriguing to see how 
it can distinguish between correlated ipsilateral inputs and correlated inputs from both epithelia. The underlying mechanism is likely to challenge the common view of a glomerulus as a simple integrator of its inputs.

Temperature plays a crucial role in the development and survival of poikilothermic amphibians. Besides determining body thermoregulation, temperature perception drives a range of behaviors in premetamorphic and postmetamorphic animals, including social aggregation of larvae, predator-evoked flight responses, food localization, basking, and burrowing (Feder and Burggren, 1992). While some of these behaviors may be mediated by crude skin thermosensation, the current study sheds light on how temperature is also involved in olfactory processing. The temperature response curves of single mitral cells indicate that temperature-sensitive cells in the olfactory bulb show different tunings (Fig. 2). Some could predict slow temperature gradients better, while others rather could detect abrupt substantial changes of temperature in the $1^{\circ} \mathrm{C}$ range. The observations suggest that the olfactory system complements sensory transduction in the skin by providing a more refined processing of thermal information. The present work focused on thermosensitivity and chemosensitivity in the olfactory bulb of premetamorphic animals. Although we did not perform any experiments in postmetamorphic $X$. laevis, previous literature indicates that the $\gamma$-glomerulus outlives metamorphosis (Gaudin and Gascuel, 2005).

We detected dual-sensitive mitral cells, which showed increased activity upon stimulation with thermal and chemical cues. Earlier work on amphibians (Browne and Edwards, 2003) has established that temperature influences food intake in frogs, and the effect of nutritional diets on growth rate and body mass of tadpoles (Alvarez and Nicieza, 2002). Briefly, the interaction of food quality and temperature noticeably altered larval size at metamorphosis: temperature changes of $5^{\circ} \mathrm{C}$ caused differences in growth rates in response to the same food diet. The integration of chemical and thermal signals in individual mitral cells, which we report in our current study, may underlie the combinatory effects of diet and temperature on larval size and development.

To our knowledge, the observation of temperature coding in mitral cell networks of the vertebrate olfactory system is unprecedented. We did not further analyze thermosensitive cells with regard to their innervation pattern, although many of them showed processes connecting with the $\gamma$-glomerulus in bolusloading experiments. Temperature-induced calcium activity was primarily observed in the presynaptic and postsynaptic neuropil of the $\gamma$-glomerulus, and in olfactory neuron afferents projecting to this structure; henceforth, our assumption that most, if not all, thermosensitive mitral cells innervate the $\gamma$-glomerulus. Importantly, the $\gamma$-glomerulus seems to respond to T-jumps only, while most thermosensitive mitral cells can be activated by chemicals. Whether this thermo-odorant cross talk is a direct or indirect effect was also beyond the scope of this article. Among the possible rationales are the activation of ligand-stimulated glomeruli or the intervention of secondary dendrites of mitral cells. While we have seen examples of the former, the latter mechanism cannot be excluded. Indeed, previous data corroborated that some mitral cells receive input from multiple glomeruli (Scheidweiler et al., 2001; Nezlin et al., 2003) and some cells innervating the $\gamma$-glomerulus appear to send their dendrites to one or more glomeruli in the neighboring clusters. Such connectivity would confer dual chemosensitivity/ thermosensitivity to some mitral cells, as described above. Alternatively, an indirect effect could involve the modulation of granule cell-mediated lateral inhibition of mitral cells via their secondary dendrites. Investigating and differentiating between the two hypotheses will be a goal of future experiments.

\section{References}

Altner H (1962) Untersuchungen über leistungen und bau der nase des südafrikanischen krallenfrosches Xenopus laevis (Daudin, 1803). J Comp Physiol A 45:272-306. CrossRef

Alvarez D, Nicieza AG (2002) Effects of temperature and food quality on anuran larval growth and metamorphosis. Funct Ecol 16:640-648. CrossRef

Bao G, Schild D (2014) Fast and accurate fitting and filtering of noisy exponentials in Legendre space. PLoS One 9:e90500. CrossRef Medline

Brechbühl J, Klaey M, Broillet MC (2008) Grueneberg ganglion cells mediate alarm pheromone detection in mice. Science 321:1092-1095. CrossRef Medline

Brechbühl J, Moine F, Broillet MC (2013) Mouse Grueneberg ganglion neurons share molecular and functional features with C. elegans amphid neurons. Front Behav Neurosci 7:193. CrossRef Medline

Brechbühl J, Klaey M, Moine F, Bovay E, Hurni N, Nenniger-Tosato M, Broillet MC (2014) Morphological and physiological species-dependent characteristics of the rodent Grueneberg ganglion. Front Neuroanat 8:87. CrossRef Medline

Browne RK, Edwards DL (2003) The effect of temperature on the growth and development of green and golden bell frogs (Litoria aurea). J Therm Biol 28:295-299. CrossRef

Byrd CA, Burd GD (1991) Development of the olfactory bulb in the clawed frog, Xenopus laevis: a morphological and quantitative analysis. J Comp Neurol 314:79-90. CrossRef Medline

Catania KC (2013) Stereo and serial sniffing guide navigation to an odor source in a mammal. Nat Comm 4:1441. CrossRef

Chao YC, Chen CC, Lin YC, Breer H, Fleischer J, Yang RB (2015) Receptor guanylyl cyclase- $\mathrm{G}$ is a novel thermosensory protein activated by cool temperatures. EMBO J 34:294-306. CrossRef Medline

Cockerham RE, Leinders-Zufall T, Munger SD, Zufall F (2009) Functional analysis of the guanylyl cyclase type D signaling system in the olfactory epithelium. Ann N Y Acad Sci 1170:173-176. CrossRef Medline

Duistermars BJ, Chow DM, Frye MA (2009) Flies require bilateral sensory input to track odor gradients in flight. Curr Biol 19:1301-1307. CrossRef Medline

Ebbesson SO, Bazer GT, Jane JA (1986) Some primary olfactory axons project to the contralateral olfactory bulb in Xenopus laevis. Neurosci Lett 65:234-238. CrossRef Medline

Feder ME, Burggren WW (Eds.) (1992) Environmental physiology of the amphibians. Chicago: University of Chicago.

Fleischer J, Hass N, Schwarzenbacher K, Besser S, Breer H (2006) A novel population of neuronal cells expressing the olfactory marker protein (OMP) in the anterior/dorsal region of the nasal cavity. Histochem Cell Biol 125:337-349. CrossRef Medline

Fuss SH, Omura M, Mombaerts P (2005) The Grueneberg ganglion of the mouse projects axons to glomeruli in the olfactory bulb. Eur J Neurosci 22:2649-2654. CrossRef Medline

Gardiner JM, Atema J (2010) The function of bilateral odor arrival time differences in olfactory orientation of sharks. Curr Biol 20:1187-1191. CrossRef Medline

Gaudin A, Gascuel J (2005) 3D atlas describing the ontogenic evolution of the primary olfactory projections in the olfactory bulb of Xenopus laevis. J Comp Neurol 489:403-424. CrossRef Medline

Gliem S, Syed AS, Sansone A, Kludt E, Tantalaki E, Hassenklöver T, Korsching SI, Manzini I (2013) Bimodal processing of olfactory information in an amphibian nose: odor responses segregate into a medial and a lateral stream. Cell Mol Life Sci 70:1965-1984. CrossRef Medline

Hanke W, Mamasuew K, Biel M, Yang RB, Fleischer J (2013) Odorantevoked electrical responses in Grueneberg ganglion neurons rely on cGMP-associated signaling proteins. Neurosci Lett 539:38-42. CrossRef Medline

Juilfs DM, Fülle HJ, Zhao AZ, Houslay MD, Garbers DL, Beavo JA (1997) A subset of olfactory neurons that selectively express cGMP-stimulated phosphodiesterase (PDE2) and guanylyl cyclase-D define a unique olfactory signal transduction pathway. Proc Natl Acad Sci U S A 94:33883395. CrossRef Medline

Junek S, Chen TW, Alevra M, Schild D (2009) Activity correlation imaging: 
visualizing function and structure of neuronal populations. Biophys J 96:3801-3809. CrossRef Medline

Junek S, Kludt E, Wolf F, Schild D (2010) Olfactory coding with patterns of response latencies. Neuron 67:872-884. CrossRef Medline

Koos DS, Fraser SE (2005) The Grueneberg ganglion projects to the olfactory bulb. Neuroreport 16:1929-1932. CrossRef Medline

Leinders-Zufall T, Cockerham RE, Michalakis S, Biel M, Garbers DL, Reed RR, Zufall F, Munger SD (2007) Contribution of the receptor guanylyl cyclase GC-D to chemosensory function in the olfactory epithelium. Proc Natl Acad Sci U S A 104:14507-14512. CrossRef Medline

Liu CY, Fraser SE, Koos DS (2009) Grueneberg ganglion olfactory subsystem employs a cGMP signaling pathway. J Comp Neurol 516:36-48. CrossRef Medline

Mamasuew K, Breer H, Fleischer J (2008) Grueneberg ganglion neurons respond to cool ambient temperatures. Eur J Neurosci 28:1775-1785. CrossRef Medline

Mamasuew K, Michalakis S, Breer H, Biel M, Fleischer J (2010) The cyclic nucleotide-gated ion channel CNGA3 contributes to coolness-induced responses of Grueneberg ganglion neurons. Cell Mol Life Sci 67:18591869. CrossRef Medline

Mamasuew K, Hofmann N, Breer H, Fleischer J (2011) Grueneberg ganglion neurons are activated by a defined set of odorants. Chem Senses 36:271-282. CrossRef Medline

Manzini I, Schild D (2003) cAMP-independent olfactory transduction of amino acids in Xenopus laevis tadpoles. J Physiol 551:115-123. CrossRef Medline

Manzini I, Brase C, Chen TW, Schild D (2007a) Response profiles to amino acid odorants of olfactory glomeruli in larval Xenopus laevis. J Physiol 581:567-579. CrossRef Medline

Manzini I, Heermann S, Czesnik D, Brase C, Schild D, Rössler W (2007b) Presynaptic protein distribution and odor mapping in glomeruli of the olfactory bulb of Xenopus laevis tadpoles. Eur J Neurosci 26:925-934. CrossRef Medline

Myers BR, Sigal YM, Julius D (2009) Evolution of thermal response properties in a cold-activated TRP channel. PLoS One 4:e5741. CrossRef Medline

Nezlin LP, Schild D (2005) Individual olfactory sensory neurons project into more than one glomerulus in Xenopus laevis tadpole olfactory bulb. J Comp Neurol 481:233-239. CrossRef Medline

Nezlin LP, Heermann S, Schild D, Rössler W (2003) Organization of glom- eruli in the main olfactory bulb of Xenopus laevis tadpoles. J Comp Neurol 464:257-268. CrossRef Medline

Nieuwkoop PD, Faber J (1994) Normal table of Xenopus laevis (Daudin). New York: Garland Publishing.

Ottoson D (1959) Comparison of slow potentials evoked in the frog's nasal mucosa and olfactory bulb by natural stimulation. Acta Physiol Scand 47:149-159. CrossRef Medline

Pinelli C, D’Aniello B, Polese G, Rastogi RK (2004) Extrabulbar olfactory system and nervus terminalis FMRFamide immunoreactive components in Xenopus laevis ontogenesis. J Chem Neuroanat 28:37-46. CrossRef Medline

Porter J, Anand T, Johnson B, Khan RM, Sobel N (2005) Brain mechanisms for extracting spatial information from smell. Neuron 47:581-592. CrossRef Medline

Rajan R, Clement JP, Bhalla US (2006) Rats smell in stereo. Science 311: 666-670. CrossRef Medline

Ramón y Cajal S (1995) Histology of the nervous system of man and vertebrates. New York: Oxford UP.

Roppolo D, Ribaud V, Jungo VP, Lüscher C, Rodriguez I (2006) Projection of the Grüneberg ganglion to the mouse olfactory bulb. Eur J Neurosci 23:2887-2894. CrossRef Medline

Scheidweiler U, Nezlin L, Rabba J, Müller B, Schild D (2001) Slice culture of the olfactory bulb of Xenopus laevis tadpoles. Chem Senses 26:399-407. CrossRef Medline

Schild D (1985) A computer-controlled device for the application of odors to aquatic animals. J Electrophysiol Techniques 12:71-79.

Schmid A, Pyrski M, Biel M, Leinders-Zufall T, Zufall F (2010) Grueneberg ganglion neurons are finely tuned cold sensors. J Neurosci 30:7563-7568. CrossRef Medline

Shinoda K, Shiotani Y, Osawa Y (1989) "Necklace olfactory glomeruli" form unique components of the rat primary olfactory system. J Comp Neurol 284:362-373. CrossRef Medline

Storan MJ, Key B (2006) Septal organ of Grüneberg is part of the olfactory system. J Comp Neurol 494:834-844. CrossRef Medline

Stosiek C, Garaschuk O, Holthoff K, Konnerth A (2003) In vivo two-photon calcium imaging of neuronal networks. Proc Natl Acad Sci U S A 100: 7319-7324. CrossRef Medline

von Békésy G (1964) Olfactory analogue to directional hearing. J Appl Physiol 19:369-373. Medline 